\title{
Instructional Designand Strategy for Legal Practice
}

\author{
T. Ninomiya and S. Teramoto
}

\begin{abstract}
An experienced instructional designer and a legal professional jointly designed an Instructional Curriculum Map ("ICM") and it's rubrics for legal practice consisting of three parts: 1) to recognize social problems; 2) to create rules; and 3) to apply and amend/interpret such created rules. The learners highly evaluated the course and learners' skill levels increased as a result of taking the course implementing the ICM, although the necessity of improvements to the administrative aspects thereof are suggested by specialists. However, through analysis, it was concluded that the course could be improved if the following changes were made, namely, 1) learners are enrolled on a pre-program to enable them to acquire the skills to think logically, and 2) redundant explanations or multiple questions are avoided when a learner fails to progress and instead the dialogue is repeated when a learner fails to progress.
\end{abstract}

Index Terms-Instructional design, layout of argument, learning strategy, legal education.

\section{INTRODUCTION}

An experienced instructional designer and a legal professional jointly designed an intensive course (the "Course") for the purpose of developing learners' skills required in legal practice, and analyzed the results of the Course. Teramoto, while acting as an instructor with one professor of law and one lecturer, managed and conducted the Course (three days from the 8th to the 10th of August, 2013; 15 learners participated).

\section{COURSE DESIGN}

In designing the Course, we employed and followed the procedure of the systems approach model of Dick \& Carey [1], one of the frequently referred to instructional design [2] models that, we considered, would enable us to effectively design an intentional learning program. The reason for employing the system approach was to consider legal practice as a system for the purpose of learning. It was hoped that the repeated application of such an approach would improve the effectiveness of our educational programs. Accordingly, from April 2014, we are going to start implementing an improved course design for one of Shinto Teramoto's undergraduate classed as Kyushu University. Therefore this paper is nothing more than the initial proposal of instructional design and strategy for legal practice.

\section{A. Instructional Curriculum Map}

Relying on Teramoto's 25 years of experience as an

Manuscript received February 7, 2014; revised April 22, 2014.

T. Ninomiya is with the Graduate School of Interdisciplinary Information Studies, the University of Tokyo, Tokyo, 113-0033, Japan (e-mail: ninomiya@iii.u-tokyo.ac.jp).

S. Teramoto is with the Graduate School for Law, Kyushu University, Fukuoka, 812-8581, Japan (e-mail: jshin768@gmail.com). attorney, we assumed that the ability "to recognize social problems and solve them by creating and applying rules" was one of the most important abilities required in legal practice.

Therefore, "having learners acquire the said ability" was set as the goal of the Course. However, not a few practitioners fail to appropriately recognize social problems, presumablydue to their lack of sufficient skill in the said ability. This suggested that the Course should not focus solely on the ability to "solve" social problems, by assuming that learners had already acquired the ability to "recognize" problems. Instead, both oftheabilities to "recognize" and"solve" problems had to be emphasized. In light of this, the following steps were set to be performed by learners: 1) to recognize social problems; 2) to create rules; and 3) to apply and amend/interpret such created rules.

We estimated that, by helping the learners to walk through these steps 1) through 3), the learners would acquire the said abilities. The Course's Instructional Curriculum Map (ICM) (Fig. 1) shows that the goal of the Course was to be achieved incrementally through the said three steps. The series of tasks that enable the learners to complete the respective steps are shown just below it (from bottom to top). Note that, according to the description method of ICM [1], [2], each of the tasks is described by identifying the lower skills necessary to perform the relevant task, and the knowledge behind the respective lower skills is depicted just left of each skill. For the convenience of instructors of law who are not familiar with ICM, our ICM shows the procedures used to examine skill and feedback to learners designed to enhance the motivation of the learners, just to the right of each skill. These mechanisms are not shown in an ordinary ICM. We then divided the Course into seven classes, each of which was designed to elaborate one integral scenario.

\section{B. Evaluation Criteria}

Our rubrics, the rating scale including guidelines for the determination of the rating [3], was defined to facilitate the assessment of the ability of learners (Table I). It contains levels 1 through 8 from the lower to higher levels of evaluation. Levels 1 through 4 correspond to STEP 1; 5 and 6 to 2 ; and 7 and 8 to 3 in our ICM. Because we assumed that STEP 1 was most material in the Course and essential for the learners to advance to the following steps, 4 levels were assigned to STEP 1 to facilitate detailed assessment. The desirable outcomes of a learner having achieved the respective levels are shown in the bottom row. Since we employed the concept of a sociogram [4] as a tool to be employed by learners to go through STEPs 1 and 2, the corresponding outcomes are also shown in the form of a sociogram. In contrast, we employed a children's book "Library Lion" [5] as a part of the course material, and requested the learners to discuss the story of the change of a rule in the book, the outcomes were expected to be presented in a literary form. 


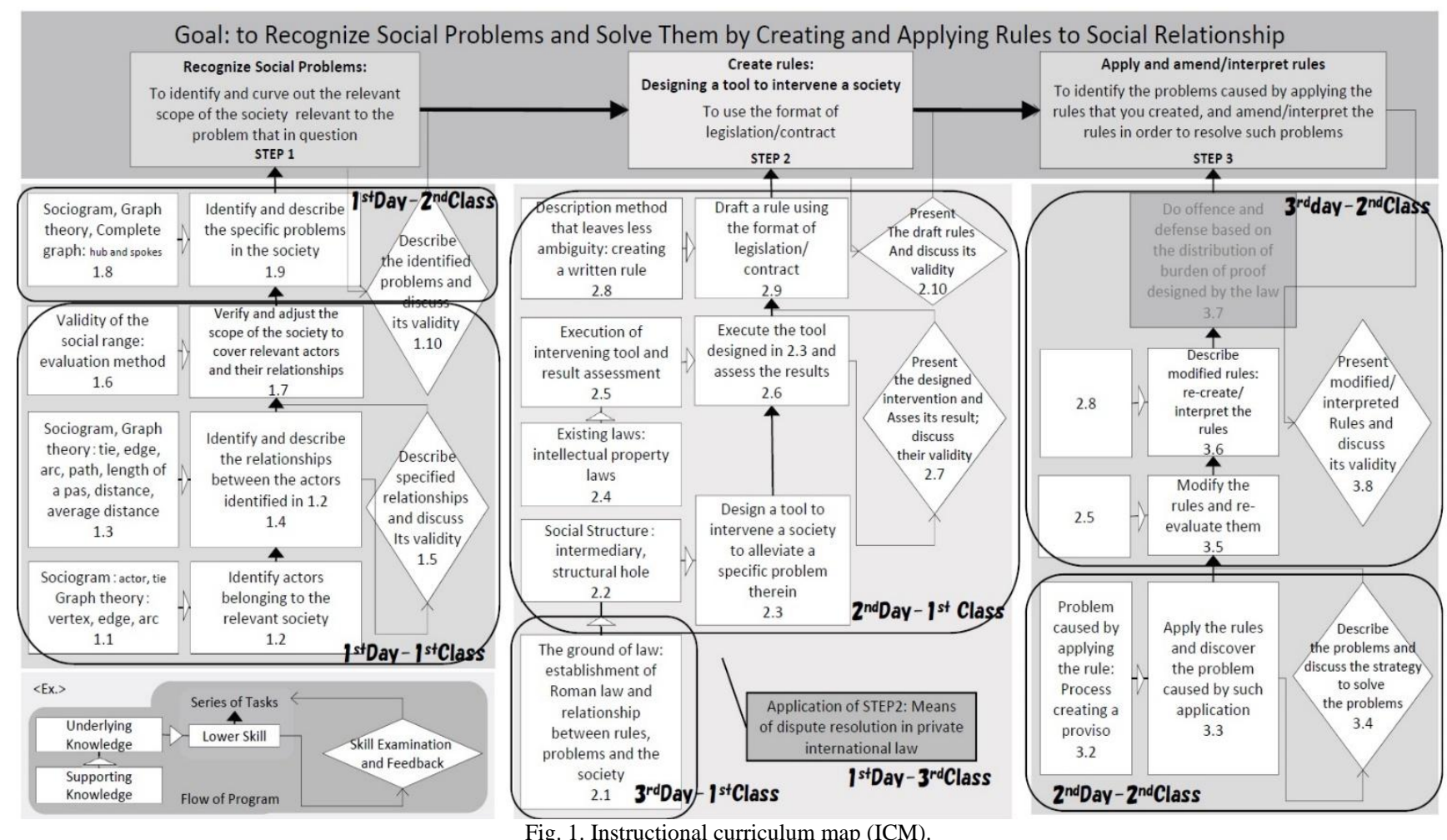

TABLE I: RATING SCALE

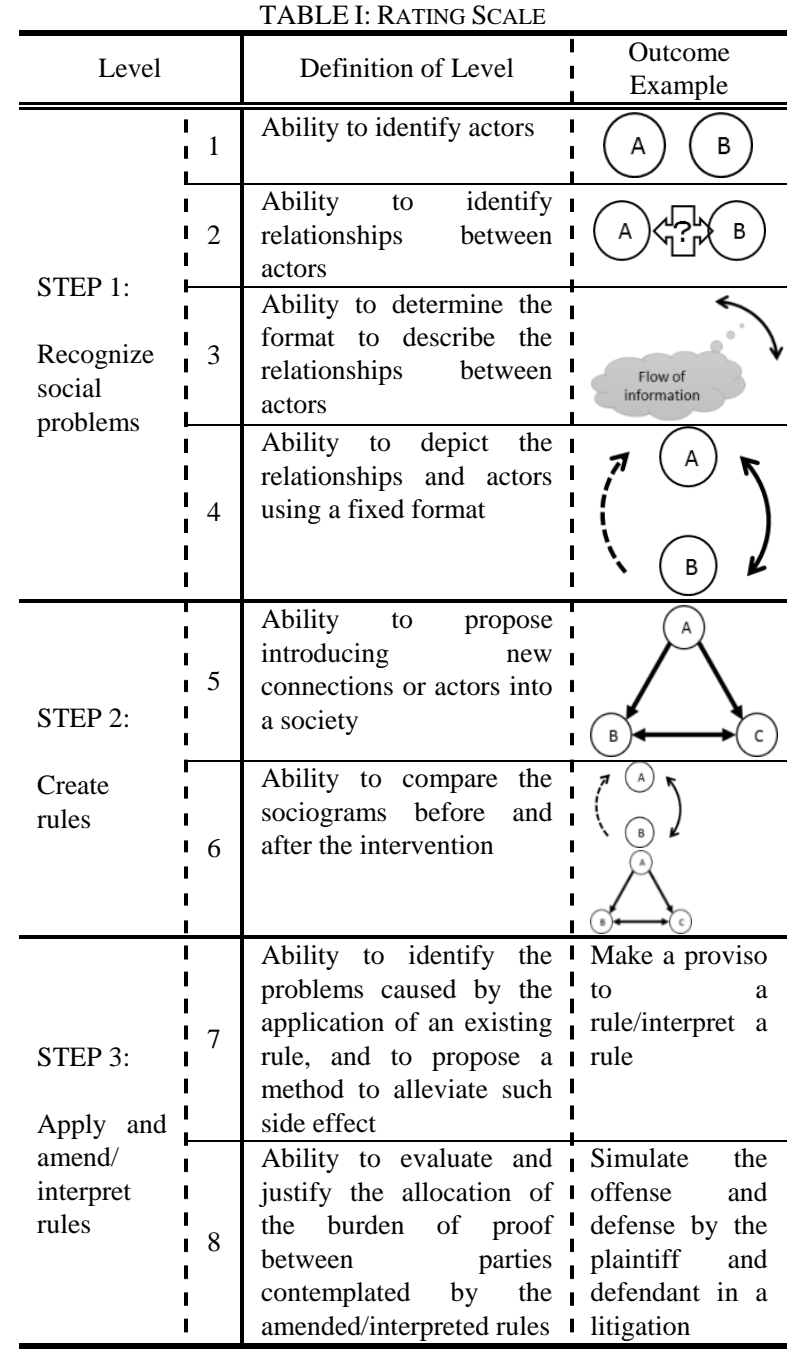

\section{Learning Strategy}

According to the experience of Teramoto, we assumed that the relevant learners could autonomously acquire the "knowledge" depicted in our ICM. Therefore, we designed the Course to emphasize the acquisition of "skills." It is generally understood that a didactic manner is unlikely to help learners acquire skills. Moreover, the skill to construct a logical reasoning to prove facts and/or persuade others to accept them is one of the typical skills essential in conducting every aspect of legal practice. It is generally accepted as the most practical method of instruction for law teachers to employ a dialogue between themselves and learners, rather than use a didactic manner. Since we had no reason to question such understanding and practice, the Course employed mainly dialogue. We schematized the procedures by which the learners deepened their learning through dialogue with their instructor, while their instructor varied his instruction to guide them effectively, depending on the respective learners' needs [6]. During the Course, the instructors employed this strategy (Fig. 2) to help learners deepen their learning.

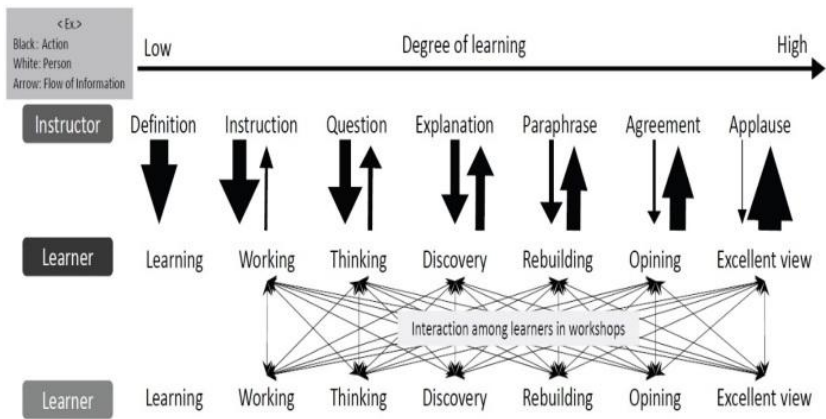

Fig. 2. Degree of learning using dialogue.

\section{EDUCATIONAL EFFECT}

The Evaluation by Learners (Fig. 3) and Experts (Fig. 4), and the Learners' level Pre and Post the Course (Fig. 5) helped us to analyze the educational effect.

The responses from learners was on the whole positive 
(Fig. 3). Items concerning the Course's contents ("Clarity of Materials", "Effect of Course") received highly positive responses. We received several negative responses from learners regarding administrative issues including the date, hour, venue, etc. Some learners would have preferred the course to have been held after working hours, or for the classes to have been held over a longer continuous period. These responses suggest that the administrative conditions should be improved for future similar courses.

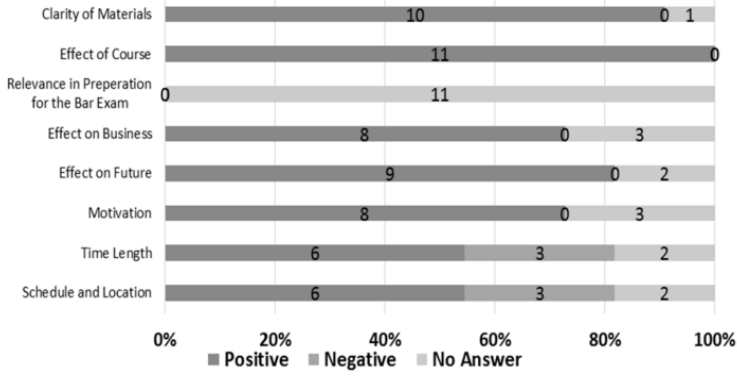

Fig. 3. Evaluation by learners (11 learners).

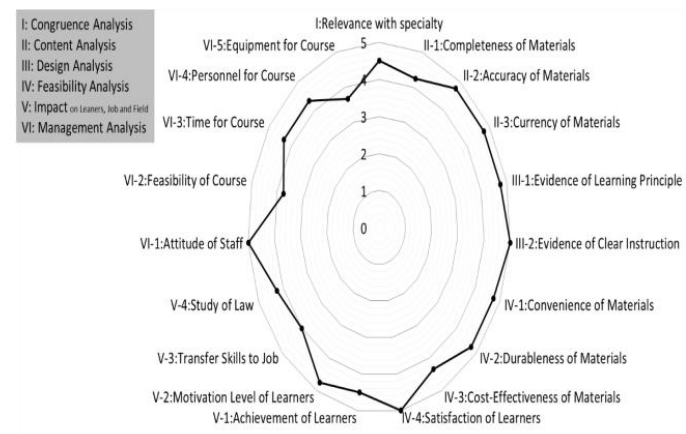

Fig. 4. Evaluation by experts (one professor, one attorney, two experts).

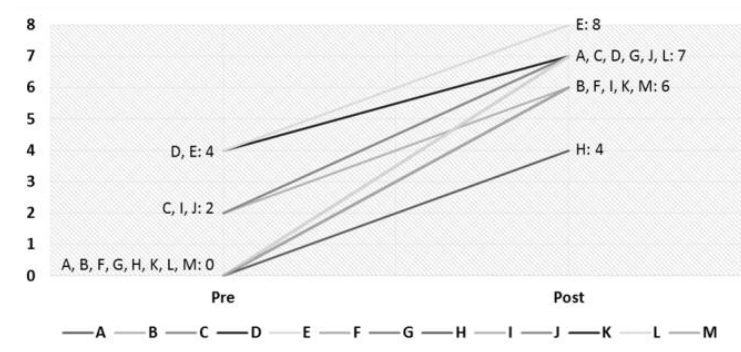

Fig. 5. Change in learners' skill level.

Congruence analysis ("Relevance with Specialty"); content analysis ("Completeness of Materials", "Accuracy of Materials", "Currency of Materials"); design analysis ("Evidence of Learning Principle", "Evidence of Clear Instruction"); and feasibility analysis ("Convenience of Materials", "Durableness of Materials", "Cost-Effectiveness of Materials" ) received quite high scores (Fig. 4). In contrast, impact on job and field ("Transfer Skills to Job" and "Study of Law"), as well as "Equipment for Course" received slightly lower scores. Presumably, this was partly because the Course was designed to have learners acquire the basic skills required, and it did not include the specific application of legal skills such as contract drafting, negotiation, litigation procedures, etc. "Feasibility of Course" also failed to receive a high score. Presumably, this was partly because we failed to design the Course's content to be portable between different instructors. It also suggests that there remains much room to improve the administrative aspect of the Course.

The levels of the 13 learners increased by 5.38 on average from pre to post the Course (Fig. 5). Two learners failed to respond because they could not attend some of the classes. The results suggest that the Course's learning strategy, namely, encouraging learners to acquire skills through dialogue, was successful.

\section{ANALYSIS CONTEXT}

\section{A. Degree of Learning}

The second class of the second day ("II-2") was the most highly rated by most of the learners. The break-down of learners' actions in II-2, as well as their respective percentages, showed that learners had exhibited "discovery" and "opining", both of which are positive actions (Fig. 6). In comparison, in the first class of the same day ("II-1") and by the same instructor (Teramoto), the majority of learners' actions were occupied by passive actions such as "learning", "working" and "thinking" (Fig. 7). This suggests that the learning aimed for by the Course was deepened greater in II-2, compared to II-1. As shown in our ICM, the structure of II-2 is much simpler than that of II-1. Presumably, covering fewer skills in one class would be more effective in helping learners acquire the relevant skills through dialogue.

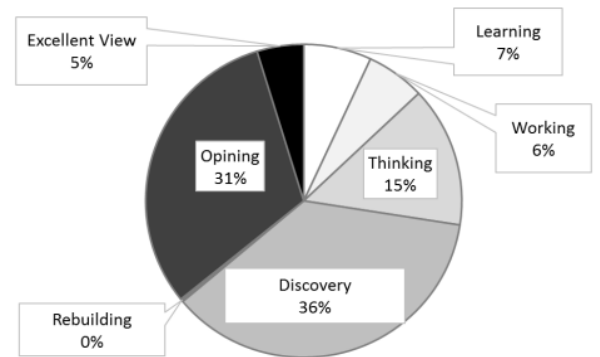

Fig. 6. Learners' action in II-2

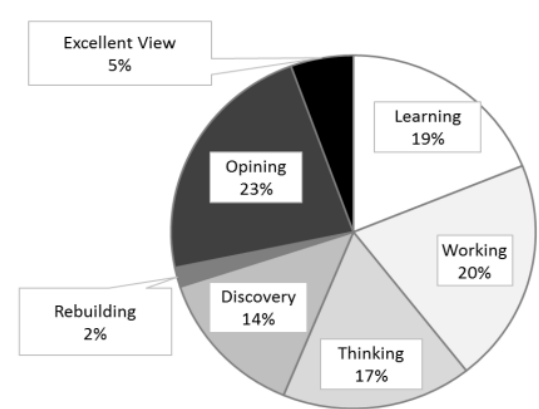

Fig. 7. Learners' action in II-1.

\section{B. Layout of Argument Appeared in Dialogue}

We analyzed the events that occurred in II-2. For this purpose, we classified the components of the dialogue over the period of one hour in the class using a Toulmin model of argument $(C$ : claim/conclusion, $D$ : data, $W$ : warrants, $Q$ : qualifier, R: rebuttal, B: backing) [7]. We found $133 \mathrm{Cs}$, each of which was generated based on $\mathrm{D}, \mathrm{W}$ or $\mathrm{B}$. We also found that the $\mathrm{C}$ of the respective dialogues, after its justification, was used as $\mathrm{W}$ or $\mathrm{B}$ in the immediately following dialogue:

1) Dialogue Ex.1. breakdown of one dialogue in ii-2 using a tourmin model of argument

- Instructor: The public library [in "Library Lion" [5]] has the rule "If you cannot be quiet, you will have to leave" (C). Suppose that I am a Lion. Tell me why such rule was established (Request W). 
- Learner: Many people are [reading books] in the library (D). A noisy person is likely to ruin their concentration (W). Accordingly, we have to keep quiet in the library (C).

- Instructor: I am not convinced (Doubt to W of Learner). Because I am a lion (D), I cannot concentrate on my book without growling (R).

We encountered two occasions where the dialogue was stuck for a while before moving to the following dialogue, and the instructor failed to make the relevant learner deepen his learning with such dialogue. On one of the said two occasions, the relevant learner tried to justify a rule (C) by using a claim not accompanied by its justification (C). Thus, the instructor tried to have the learner understand that a claim without justification (C) can hardly be $\mathrm{W}$ or $\mathrm{B}$ justifying a rule $(C)$. This unsuccessful trial was repeated six times employing different examples each time. Presumably, redundant explanations with varied examples did not help the learner's understanding, but instead embarrassed him. On another of the said occasions shown below, the instructor failed to make a learner change and improve his response, presumably because the instructor's pressing questions made it difficult for the learner to discern which matters in his questions corresponded to $\mathrm{D}, \mathrm{W}, \mathrm{B}$ or $\mathrm{C}$ respectively.

2) Dialogue Ex2.failure response

- Instructor: [Your reasoning] is a typically weak one (C) against the counter contentions such as "which opinion is dominant (Learner's B) in reality?" or "do statistics support (R) your contention?" Moreover, [you] stated that because the rule had been applied (Learner's D), certain results were produced (Learner's C, and following D) - that is, libraries segregate the areas where you may eat and drink from the areas you are expected to read books quietly (Learner's D). However, this fact cannot justify the rule (the relevant $D$ cannot be $\mathrm{W}$ and/or B of the relevant C). You contend that because the rule had been established and applied (Learner's C), something occurred (Learner's D), and, accordingly the rule was established (Learner's C, which is the same as the first Learner's C). You are just making a circular argument ( $\mathrm{C}$ and $\mathrm{D}$ derived from $\mathrm{C}$ itself hardly justifies the same $\mathrm{C}$ ). Because the rule is established and applied, something happened (D). The majority of the library users may be happy with such results (W). However, unless you explain why they are happy with such results (B), who can know why the rule was established or maintained.

- Learner: (he just repeated the same explanation that was rejected by the instructor.)

We also found that another learner correctly understood the said explanation by the instructor, and gave the response below by responding in place of the said learner:

3) Dialogue Ex3.successful response

- Leaner: My argument is from a different perspective (change the domain of B). I admit that reading aloud is [often] convenient [for our better understanding of a book] (D). That you read a book (D) means that you are trying to understand the contents thereof $(\mathrm{W})$. However, the noise entering your ears is likely to be an obstacle to your attempt to understand the series of characters that you see (B). As a result, you cannot understand what is written in the book $(\mathrm{W})$.... Therefore, we are trying to be quiet [in the public library] (C).

On the said two occasions, the instructor employed conventional and customary means to proceed the dialogues at law schools in order to have a learner recognize his/her inadequate argument. That is, the instructor waited until the learner provided a better argument by posing multiple questions. The said analysis suggests that whether or not this method can guide learners to acquire the relevant skills entirely depends on their pre-existing ability to understand the instructors' questions.

\section{CONCLUSION}

Our analysis of the Course suggests that a two-pronged approach could be useful to improve the course design: one is to prepare a pre-program oriented to have learners acquire the skills to think logically and make logical presentations; and another is to avoid redundant explanations or multiple questions, and to just return to the former dialogue when the instructor finds a learner stuck in the mud.

\section{REFERENCES}

[1] W. Dick, L. Carey, and J. O. Carey, The Systematic Design of Instruction, 7th ed., New Jersey: Pearson Education Inc., 2009.

[2] R. M. Gagne, W. W. Wager, K. C. Galas, and J. M. Keller, Principles of Instructional Design, 5th ed., CA: Wadsworth Cengage Learning, 2005.

[3] D. D. Stevens and A. J. Levi, Introduction to Rubrics, 2nd ed., Virginia: Stylus Publishing, LLC, 2013.

[4] J. Scott, Social Network Analysis, 3rd ed., CA: SAGE Publications Limited, 2013.

[5] M. Knudsen and K. Hawkes, Library Lion, MA: Candlewick, 2006.

[6] P. Kreeft, Socratic Logic, 3.1 ed., Indiana: St Augustine's Press, 2010.

[7] S. E. Toulmin, The Uses of Argument, Updated ed., New York: Cambridge University Press, 2003.

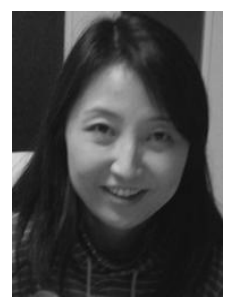

Toshie Ninomiya was born in Japan in 1970. She graduated from the department of Administration Engineering, Faculty of Science and Technology, Keio University, Japan in 1993, and studied at the Social, Genetics and Developmental Psychiatry Research Centre, Kings College London, UK.

She is a project researcher at the Graduate School of Interdisciplinary Information Studies, the University of Tokyo, Japan and worked at Toyota Motor Corporation as an engineer, Keio University as an intake counselor, Ibaraki University as an engineering official and the University of Electro-Communications as an assistant professor. Her research interests are in education systems for experts and visualization of implicit knowledge.

Ms. Ninomiya received an Overseas Research Student Award from the Committee of Vice-Chancellors and Principals of the Universities of the United Kingdom in 1997.

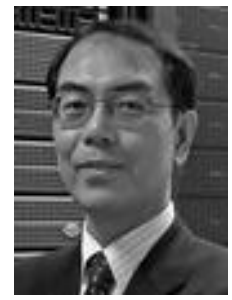

Shinto Teramoto was born in Japan in 1963. He passed the National Bar Examination of Japan in 1984 and received his Bachelor of Laws from the Faculty of Law at the University of Tokyo, Japan in 1985. After he completed the requisite judicial training course at the Legal Training and Research Institute of Japan, he started his career as a legal practitioner in 1987.

As an attorney, he specialized in venture capital finance and intellectual property law for over 20 years Currently he is a professor at the Faculty of Law, Kyushu University, Fukuoka, Japan. Prior to joining the university in 2010, he was a Professor at the Graduate Schools for Law and Politics, the University of Tokyo. His research interests are in social network perspective of intellectual property law and legal education.

Prof. Teramoto was selected as one of the Best Lawyers in Japan for 2013 in the area of intellectual property. He is a member of several academic associations including INSNA and the Intellectual Property Association of Japan. 